\title{
RESENHA: GULASEKARAM, PRATHEEPAN; RAMAKRISHNAN, KARTHICK S. THE NEW IMMIGRATION FEDERALISM. NEW YORK: CAMBRIDGE UNIVERSITY PRESS, 2015.
}

\author{
REVIEW: GULASEKARAM, PRATHEEPAN; RAMAKRISHNAN, KARTHICK S. THE \\ NEW IMMIGRATION FEDERALISM. NEW YORK: CAMBRIDGE UNIVERSITY PRESS, \\ 2015.
}

\section{Roberta Maria Botelho Bevilacqua ${ }^{1}$}

Os Estados Unidos como nação teve na base de sua origem a imigração, sendo essa justamente daqueles indivíduos preteridos pela Coroa britânica no século XVII. A partir da adoção do federalismo como sistema político, o qual forneceu uma centralização necessária para a construção do país que se observa hoje, o controle sob a imigração se tornou uma necessidade latente, a qual foi cada vez mais atrelada ao governo central. Todavia, como Pratheepan Gulasekaram e Karthick Ramakrishnan² elucidam, não se deve apenas considerar o âmbito federal na formulação e implementação de políticas relacionadas à temática imigratória, cabendo também destaque ao envolvimento dos governos locais, especialmente frente ao federalismo particular existente nos Estados Unidos.

Os autores em questão estão inseridos em um contexto particularmente favorável a condução de uma pesquisa que destaque a atuação de governos subnacionais na temática imigratória, que é o estado da Califórnia. Desde os anos 1990, o proativismo que a região tem empregado, desenvolvendo leis e políticas próprias, a coloca como destaque no cenário nacional, fortalecendo as possibilidades de engajamento desses atores nesta arena. Nos últimos anos, e especialmente após o início da presidência de Donald Trump, a Califórnia se tornou protagonista no movimento das cidades-santuário, ou cidades rebeldes, as quais buscam implementar medidas locais pró-imigração e se colocam como resistência direta ao seu mandato.

De forma a combinar as áreas de pesquisa dos autores - o lado jurídico e o da ciência política - e o próprio contexto em que estão inseridos, o livro "The new immigration federalism" (2015) surge como uma possibilidade de resposta para algumas questões envolvendo o relacionamento entre governo federal e governos subnacionais nos EUA na temática imigratória, dentro do arcabouço teórico denominado federalismo imigratório. Tal literatura é pouco explorada

\footnotetext{
${ }_{1}^{1}$ Mestranda do Programa de Pós-Graduação em Relações Internacionais da Universidade Federal de Uberlândia. ORCID: https://orcid.org/0000-0001-7908-5251. E-mail: robevilacqua5@hotmail.com.

2 Pratheepan Gulasekaram é atualmente professor de Direito na Santa Clara University, tendo seus estudos baseados na dinâmica política e legal dos regulamentos estaduais e municipais sobre imigração, e seu efeito nas políticas federais. Já Karthick Ramakrishnan é professor de Política Pública e Ciência Política na University of California, e estuda a participação cívica, a política de imigração e as políticas de raça, etnia e imigração nos Estados Unidos.
} 
ao longo da obra, havendo uma série de indicações de leitura que indicam a origem e conceitualização do termo. Destarte, pode-se apontar que os estudos sobre federalismo imigratório representam as maneiras pelas quais os estados e as localidades poderiam se envolver tanto na construção quanto na implementação de leis e políticas relacionadas à imigração e imigrantes (VARSANYI ET AL, 2012).

O que se pode afirmar é que tal teoria refuta a perspectiva tradicional de que a imigração é uma arena de prerrogativa exclusiva de ação do governo federal, considerando-a uma política intermestic $^{3}$. Ademais, Gulasekaram e Ramakrishnan acabam, mesmo que de forma indireta, explorando as particularidades do sistema federalista estadunidense, principalmente em relação à necessidade de que o governo federal tem de que as localidades colaborem com a aplicação dos direcionamentos e prioridades de enforcement imigratório para que a política funcione no geral. Ao desmarginalizar o papel dos governos subnacionais, a obra se torna coerente com a proposta inicial de inclusão destes atores nas considerações acerca da formulação da política imigratória do país, sendo este seu primeiro grande ponto positivo.

Dessa forma, os autores buscam compreender de quais maneiras os governos subnacionais, mais especificamente os estados, se inserem no debate de federalismo imigratório, através de um foco analítico para o pós-2001. Cabe ressaltar que, ao se tratar do país como um todo, o panorama de imigração nos EUA se torna caótico no contexto inicial analisado. Os atentados terroristas de 11 de setembro de 2001, cometidos contra as Torres Gêmeas do World Trade Center e ao Pentágono, foram símbolo do início do desenvolvimento de políticas federais de imigração de cunho cada vez mais restritivos, sob o argumento de que os crimes foram cometidos por imigrantes em solo estadunidense.

Nos anos posteriores, especialmente durante os anos da administração de George W. Bush, o poder executivo se baseou em uma estratégia, elaborada pelo Conselho Nacional de Segurança dos Estados Unidos e pelo próprio presidente, a qual previa uma atuação forte, tanto em âmbito externo quanto interno. No plano externo, as ações seriam pautadas na forma de concessão de poderes ao presidente para atacar grupos terroristas em qualquer lugar do mundo; em âmbito doméstico, foram criados instrumentos legais para um maior controle de atividades individuais, principalmente em relação a vida do imigrante (ALVES PEREIRA, 2006).

Todavia, é também nesse período que se passa identificar um maior engajamento dos governos subnacionais na questão imigratória, cabendo assim o início do marco-temporal da obra. Isto posto, a partir de um mapeamento de legislações estaduais sobre imigração aprovadas nesse período, os autores focam em investigar as causas desse desenvolvimento, bem como as

\footnotetext{
${ }^{3}$ Varsanyi et al (2012) demonstram que a questão do enforcement imigratório poderia ser descrita como uma política "intermestic", ou seja, que se enquadra na conjuntura da política externa e doméstica do país. Dessa forma, as implicações da aplicação das leis são significativas para tanto para indivíduos e localidades, quanto também podem ter ramificações internacionais.
} 
implicações geradas para o relacionamento entre os entes federativos e para o próprio arcabouço teórico de federalismo imigratório.

Baseando-se nesta ideia central, a obra se divide em uma introdução e seis capítulos. Ao se observar a estrutura criada, nota-se o papel preponderante do aspecto jurídico para a compreensão do fenômeno analisado, especialmente ao destacar o papel da Suprema Corte e do Congresso dos EUA na definição do relacionamento entre o governo federal e os estados ao longo dos séculos. Este fator se torna tão importante para a análise que, para os autores, é justamente uma modificação no padrão da relação entre esses atores que marcaria o surgimento de uma nova fase de federalismo imigratório.

Logo, para Gulasekaram e Ramakrishnan, seriam três momentos de federalismo imigratório visualizados até hoje dentro dos Estados Unidos: de 1776 a 1875, de 1875 a 1965 e de 1965 aos dias de hoje. Na primeira fase, os governos locais regulavam a imigração quase que de forma exclusiva, por meio de sistemas de controle imigratório desenvolvidos nos estados. Já após 1875, nota-se que o governo federal toma para si a prerrogativa de regular a questão, limitando a ação local e criando seu próprio arcabouço legislativo e sistemas de controle da imigração. A partir de 1965, por diversas razões, é possível perceber que o governo federal passa a delegar funções aos governos subnacionais, de forma a criar uma ideia de autoridade compartilhada sobre a temática imigratória.

Esta ideia de delegação pode ser visualizada especialmente após os atentados terroristas de 2001 nos EUA. É nesse período que se nota um boom no ativismo subnacional na temática imigratória, institucionalmente embasado nas novas legislações federais estabelecidas durante a década de 1990, as quais permitiram e até mesmo encorajaram a participação dos governos locais em questões de imigração. Assim, neste momento da terceira fase de federalismo imigratório, estados e localidades se reintroduziram agressivamente no campo regulatório, propondo e aprovando várias leis de destinadas a controlar a imigração e a vida dos imigrantes ${ }^{4}$.

Todavia, até 2012, pode-se perceber que o envolvimento estadual e local através de políticas restritivas se revelou não apenas motivado por incentivos federais, sendo também tradicionalmente associados a uma crescente pressão demográfica, causada pela chegada de imigrantes a "novos destinos" no país, e a inação federal na aprovação de reforma dos estatutos de imigração existentes a nível nacional. Nesse sentido, autoridades passaram a utilizar de tais argumentos para explicar o sucateamento de diversos serviços sociais e então fundamentar o caráter restritivo de tais políticas para imigrantes.

\footnotetext{
${ }^{4}$ De acordo com Elias (2013) esse tipo de legislação imigratória, conhecida como leis de alienação, podem ser promulgadas pelo governo federal ou pelas localidades, versando, essencialmente, sobre os direitos, privilégios e obrigações dos não-cidadãos presentes nos Estados Unidos. Por outro lado, existem também as leis de imigração, as quais regem a seleção, admissão e exclusão de não-cidadãos com base em uma Lei de Imigração e Nacionalidade ("INA"), sendo de competência exclusiva do governo federal.
} 
Contrapondo esses argumentos, Gulasekaram e Ramakrishnan buscam demonstrar que outro fator foi crucial para esse direcionamento local: o político-partidário. Através de uma análise empírica estatística, os autores apontam que os fatores relacionados à imigração, como demografia e inação do Congresso, não seriam tão relevantes quanto os contextos políticos vividos por essas localidades. Nesse momento, é possível perceber que somada à vertente jurídica, o elemento político também é incorporado, deixando então as análises do final do terceiro capítulo em diante mais robustas e fundamentadas no cerne do argumento dos autores.

Assim, ao sobrepor o levantamento sobre aprovação de legislações estaduais sobre imigração, seu caráter majoritariamente restritivo e as variáveis demográficas, econômicas e políticas, os autores puderam demonstrar a inabilidade das duas primeiras em explicar a ocorrência desse tipo de posicionamento. No caso específico da legislação restritiva, nota-se que essa é significativamente mais provável em estados onde o Partido Republicano predomina. Desta forma, o problema do aumento da aprovação de legislações desse cunho seria explicado não por um simples aumento na quantidade de imigrantes em uma localidade, mas sim por este aumento ocorrer em regiões republicanas.

Já a desconstrução do argumento sobre inação federal em promover uma reforma imigratória não é totalmente consolidado. De acordo com os autores, enquanto o Congresso tem sido assolado por divisões partidárias que impedem a aprovação de novas leis imigratórias, o Executivo tem sido ativo, principalmente nas redefinições de prioridades e alocações de recursos. No entanto, a abordagem se torna problemática, pois, pensando no longo prazo, medidas implementadas por presidentes podem ser facilmente modificadas, o que não ocorreria caso leis fossem implementadas. Por tal razão, essa inabilidade de desenvolver uma legislação que se adapta ao contexto atual vivido pelos EUA ainda deveria ser considerada como um incentivo forte para o engajamento de governos subnacionais nessa temática.

Por mais que haja esse contraponto, ao longo do capítulo quatro Gulasekaram e Ramakrishnan desenvolvem um modelo mais abrangente de análise chamado de "Modelo da Mudança Polarizada", que surpreende ao substituir as explicações tradicionais que versam sobre a formulação de políticas imigratórias. Dessa forma, o argumento principal trazido é que todo esse processo de transformação de políticas sobre imigração, que engloba desde a formação de opinião de eleitores até a definição de agenda e legislação nos níveis nacional e subnacional, foi moldado pelo trabalho de partidos políticos e empreendedores. Neste caso, os empreendedores seriam aqueles que fazem o trabalho de promover questões específicas, oferecendo quadros para a compreensão dessas ao fornecer soluções e identificar oportunidades e locais para a mudança de políticas.

É importante ressaltar que o modelo pode ser aplicado tanto em âmbito nacional como subnacional, o que facilita a compreensão do posicionamento dos diferentes níveis governamentais sobre a questão imigratória, bem como sua correlação. Nesse ponto, a ideia é a 
de demonstrar a existência de um ciclo dinâmico e retroalimentado entre as legislações federais e subnacionais, ambas englobadas dentro da estrutura federalista particular dos EUA.

A partir de uma análise do modelo proposto, pode-se perceber que é dada uma ênfase a esses empreendedores, tendo esses um papel central na criação de condições para que o envolvimento subnacional em questões de imigração fosse aceito, tanto em nível jurídico quanto político. Desta maneira, o ativismo dos empreendedores somado a estrutura partidária existentes resultaram no avanço de uma agenda restritiva na temática imigratória, podendo essa ser visualizada através dos direcionamentos do governo federal e na proliferação de legislações restritivas pelos governos estaduais. O ápice dessa atuação acaba ocorrendo no segundo mandato de George W. Bush, em que se observa uma exacerbada polarização política, a qual levou a um maior incentivo para o ativismo subnacional, de forma que esses atores também fizessem parte da "solução" para o problema que era a imigração.

Com o início da administração Obama, em 2008, os empreendedores que apoiavam a existência de legislações restritivas nos níveis locais tiveram seu trabalho evidenciado, porém, começaram a perder força em 2012. Para Gulasekaram e Ramakrishnan, alguns fatores foram críticos para a transformação no posicionamento dos governos subnacionais, relacionados, essencialmente, a desenvolvimentos políticos e legais. Dentre eles, três se destacam: a decisão da Suprema Corte sobre o caso da lei SB 1070 do Arizona; a implementação do DACA (Deferred Action for Childhood Arrivals) por Obama; e a derrota do Partido Republicano nas eleições presidenciais de 2012.

Tais eventos enfraqueceram o poder dos empreendedores que vinham trabalhando para a implementação de políticas restritivas, levando, em contraposição, ao fortalecimento da agenda pró-imigração e de seus defensores. Assim, os autores argumentam que o ano de 2012 marcou um turning point para o desenvolvimento de políticas imigratórias no âmbito subnacional, as quais se tornaram, majoritariamente, integracionistas.

Nesse momento, de certa forma contrariando o argumento de que a inação federal não seria um fator tão relevante para um maior ativismo subnacional na temática, Gulasekaram e Ramakrishnan apontam que, justamente pela percepção de que uma reforma imigratória não viria tão cedo, restaria aos estados a promulgação dessas legislações pró-imigrante. Assim, se beneficiando desse entendimento, diversas políticas e leis foram implementadas a nível estadual e local, como emissão de carteiras de habilitação para imigrantes, acesso a serviços públicos e mitigação do enforcement federal.

Assim, da mesma forma com que realizaram uma análise empírica relacionando o fator político-partidário às localidades que vinham promulgando medidas restritivas, os autores da obra dedicam parte do quinto capítulo para fazer o mesmo considerando esse novo contexto apresentado. Os resultados obtidos nesse momento indicam um padrão ao se pensar a questão partidária: que os contextos políticos locais são importantes na maioria das regiões que 
implementam uma agenda integrativa. Por isso, pode-se concluir que as áreas de tendência democrata são muito mais propensas a implementar políticas integracionistas do que aquelas republicanas.

Neste ponto, é interessante observar que somada à força do fator partidário, Gulasekaram e Ramakrishnan indicam uma nova variável, que teria a mesma capacidade de influenciar o ativismo subnacional, sendo essa a proporção de latinos no estado. De acordo com o levantamento, aqueles estados com uma maior proporção de latinos e imigrantes naturalizados são significativamente mais propensos a aprovar legislações integracionistas. A única exceção foi o estado do Arizona, cuja tendência é a de implementar, majoritariamente, medidas restritivas, mesmo contando com mais de 2 milhões de latinos.

Considerando então as análises desenvolvidas, os autores da obra buscam demonstrar como os elementos incorporados têm potencial transformador para o próprio arcabouço teórico de federalismo imigratório. O que se pode perceber é que essa forma de compreender a teoria visa, essencialmente, ir além das explicações tradicionais envolvendo o fenômeno, as quais envolvem questões como a descentralização decisória ao redor da estrutura federalista estadunidense e a ideia de exclusividade de ação do governo federal em questões de imigração.

Como consequência desses novos desenvolvimentos teóricos, percebe-se que uma das mais importantes novas características do federalismo imigratório é que o próprio federalismo dos EUA passa a ser considerado justamente a base que fundamenta esse ativismo subnacional visualizado. Assim, para Gulasekaram e Ramakrishnan, o federalismo tornou-se o suporte constitutivo e retórico para a ocorrência de uma disputa partidária multinível sobre a política de imigração. Ao colocar o fator político-partidário como central, os autores fogem das narrativas tradicionais que deixam de captar essas nuâncias práticas que cercam o ativismo subnacional na temática imigratória, o que torna a compreensão do fenômeno do envolvimento de atores subnacionais muito mais complexa e robusta.

Logo, o debate proposto pelos autores tem forçado a reconsideração da natureza do federalismo em si, já que as formas pelas quais os estados e as localidades se envolvem na política de imigração e as consequências desse envolvimento estão se transformando. Um exemplo claro dessa mudança são as próprias respostas judiciais às medidas subnacionais, as quais revelam preocupações mais específicas com a metodologia utilizada para avaliar a legalidade desses regulamentos de imigração estaduais e locais, principalmente no sentido de avaliar se uma lei é de alienação ou de imigração.

Dessa maneira, o modelo que emerge, de acordo com os autores, aponta que as jurisdições estaduais e locais se tornaram essencialmente fóruns alternativos para travar batalhas ideológicas no que tange a política de imigração. Justamente pelo fato de o país viver um período prolongado de impasse no Congresso, o papel regulador do poder executivo se tornou primordial para o desenvolvimento de uma política nacional, levando assim a visualização de um 
engajamento subnacional utilizado como campo de oposição política, principalmente entre localidades anti-imigração e um governo federal pró-imigração, e vice-versa.

Por fim, tentando demonstrar as novas características do federalismo imigratório estadunidense nesse período, Gulasekaram e Ramakrishnan reforçam a importância que os empreendedores tiveram para o movimento que se formou dentro do país. Entre 2001 e 2012, pode-se observar uma fase de ações coordenadas entre o governo federal e os governos subnacionais, as quais envolveram um conjunto mais robusto de atores. De 2012 até o momento, com a onda integracionista desse ativismo, para além do papel dos empreendedores, deve-se destacar também o posicionamento proativo que organizações nacionais passaram a ter.

De forma a pensar em um cenário futuro para os Estados Unidos, Gulasekaram e Ramakrishnan fazem algumas considerações. Em primeiro lugar, apontam a tendência de que continue havendo um impasse para a aprovação de reformas na legislação imigratória nos próximos ciclos de eleições federais. Como se pode observar, quatro anos após a publicação da obra, Obama não conseguiu resultados nessa arena e Trump, com uma posição radical sobre questões imigratórias, também não vem obtendo sucesso, além de estar enfrentando grande resistência - principalmente local - nas medidas que consegue implementar.

Sobre o conteúdo das próximas reestruturações da legislação imigratória, os autores colocam que, devido a mais de uma década de maior proativismo subnacional na temática, o Congresso será forçado a reconhecer, incorporar e assimilar as preferências e políticas estaduais e locais. Então, o novo regime federal, se um dia for concretizado, será moldado pelas novas características do federalismo imigratório, devendo, portanto, abarcar tanto um engajamento através de políticas integracionistas, em lugares como Califórnia e Nova York, quanto as medidas restritivas de lugares como Arizona e Alabama. No entanto, cabe o adendo de que se antes já se tornava difícil conceber um cenário em que Republicanos e Democratas entrassem em um consenso, ao incorporar também as possibilidades subnacionais nesse cálculo, talvez essa reforma esteja ainda mais no futuro do que se pensa atualmente.

Em suma, a partir das considerações elucidadas na obra "The new immigration federalism", Gulasekaram e Ramakrishnan conseguem de forma surpreendente demonstrar a importância das localidades na formulação e aplicação da política imigratória nos Estados Unidos, especialmente por associarem a essa o caráter político-partidário, muitas vezes marginalizado. Pensando para além das teorias tradicionais, pode-se dizer que os autores da obra se mostram extremamente preocupados com esse fator, chegando a criar um modelo analítico e com possibilidades de verificação empírica, algo ainda pouco utilizado nas ciências sociais e políticas.

De modo geral, a obra consegue atingir seu objetivo de demonstrar como as localidades estadunidenses têm ganhado espaço no contexto atual de federalismo imigratório, bem como suas motivações e relevância para uma a condução favorável ou não da política imigratória. Todavia, é importante ressaltar que, para além do fator político-partidário, a enorme inatividade do 
Legislativo nessa arena ainda é um elemento crucial, tanto por fornecer um espaço de atuação à essas localidades, quanto pelo fato de não haver regulamentação específica acerca do tipo de atividades que podem ser exercidas por esses outros níveis. Nesse sentido, a obra peca em não explorar tais considerações, o que não exclui sua extrema relevância para a consolidação do campo de estudos sobre a atividade de governos subnacionais, especialmente nos EUA.

* Artigo recebido em 08 de julho de 2019, aprovado em 27 de outubro de 2019.

\section{REFERENCIAS}

ALVES PEREIRA, Antônio Celso. Direitos Humanos e terrorismo. In: SACRAMENTO, Daniel; GALDINO, Flávio (orgs). Direitos Fundamentais: estudos em homenagem ao Professor Ricardo Lobo Torres. Rio de Janeiro: Renovar, 2006.

ELIAS, Stella Burch. The New Immigration Federalism. Ohio State Law Journal, Columbus, v. 74, n. 5, p.704-752, out. 2013.

GULASEKARAM, Pratheepan; RAMAKRISHNAN, S. Karthick. The New Immigration Federalism. New York: Cambridge University Press, 2015. 304 p.

VARSANYI, Monica et al. A Multilayered Jurisdictional Patchwork: Immigration Federalism in the United States. 2012b. Law and Policy, Denver, v. 34, n. 2, p.138-158, abr. 2012. 